6

\title{
VEGA*: Cooperating Support Systems for Virtual Enterprises
}

Prof. Dr. A. R. Probst, J.-F. Bitschnau

Université de Lausanne, HEC, Inforge, 1015 Lausanne

BFSH-1, 1015 Lausanne,

tel. 021-692 34 30, fax 021-69234 05,

Andre-Rene.Probst@hec.unil.ch

Prof. Dr. J. Griese, B. Suter

Universität Bern, IWI (Abt. Informationsmanagement), Enge-

haldenstr. 8, 3012 Bern

\begin{abstract}
This paper presents some first practical results obtained in the framework of the ongoing VEGA* project. It discusses the analysis of concrete business cases which have been used first in order to determine the potential of industry sectors for virtual organizations. These cases have also been exploited to determine, in a first iteration, the general requirements for virtual enterprises cooperating support systems and to find generic aspects which can be exploited in the specification of reference models. The analysis of the cases allowed us also to point to some very practical issues which have to be taken into account for the design of a systematic approach for designing and developing this type of systems.
\end{abstract}

\section{Keywords}

Virtual Enterprise, strategic networks, Virtual Enterprises' Support Systems. 


\section{INTRODUCTION}

As a result of several trends (economical, technological, and social) today's corporations, especially Small and Medium Enterprises (SME) face enormous pressure to form alliances and to collaborate (see for example (Bentley et al., 1995), (Birchall, Lyons, 1996), (Collins, Porras, 1995), (Hagel, Armstrong, 1997)). The economic environment is getting always more turbulent, instable, uncertain and extremely competitive. Markets are both globalized and fragmented. Products' life cycles must be continually reduced. New sophisticated products are proliferating rapidly. The contribution of services in almost any value added chain is increasing constantly against the pure production part. Customers are requiring always more customized products and services, at lower prices, as well as comprehensive solutions. Technological innovations are bursting and spreading at accelerating pace. This is by no means an exhaustive list of all the problems today's corporations are confronted with. These problems are especially representing a big challenge for SME.

Everybody is preaching flexibility, innovation, swiftness in order to be able to survive and prosper. Large international business is moving from conglomerate to an organization consisting of a collection of units with core competencies, building a network of strategically structured business cells. A similar movement can be observed among smaller firms, which focus on their competencies and begin to build strategic networks. This trend is accelerating moreover that customers are requiring global solutions customized to their need. Customers are less and less willing to search at different locations for partial solutions which they have to assemble by themselves. Enterprises, of any dimension, are forced to change their processes, their organization and the way they are working and doing business, and to better exploit the facilities offered by the new information and communication technologies. Companies are radically rethinking their strategies, and engaging in strategic alliances (Erkes et al., 1996). Considering the range of possible partnerships an organization can undertake, planners have to make the choice of the co-operative strategy they will implement to build their companies' core competencies and their market position, the choice of relationship or tie bonding the partners together and, of course, the choice of the partners. In order to be able to face large competitors on local markets as well as to have better access to international markets SME are increasingly choosing (implicitly or explicitly) to form "virtual enterprises" (see for example: (Frankwick et al., 1995), (Goldman et al., 1995), (Goldschmitt, 1996), (Grenier, Metes, 1996), (Handy, 1995), (Hardwick et al., 1996), (Heskett et al., 1997), (Hinterhuber, Levin, 1993), (Maier, Traxler, 1995), (Maillat et al., 1990), (Martin, 1996), (Moore, 1996), (NIIIP, 1996), (Probst et al., 1996), (Upton, McAfee, 1996)). 
Many definitions have been given, of course, to the concept of "virtual enterprise". We will not give here another definition and enter in the debate for finding the best one see, for example, (Arnold et al., 1995), (Chesbourg, Teece, 1996), (Davidow, Malone, 1992), (Griese, 1997), (Mertens, Faisst, 1995), (Probst et al., 1996)).

\section{THE VEGA* PROJECT}

\subsection{Objectives of the VEGA* Project}

The objectives of the VEGA* project are, on the one hand to propose organizational as well as Information Systems frameworks. These frameworks should facilitate the set-up and the development of specific Virtual Enterprise's organizations and the implementation of cooperating support systems for these virtual organizations. The focus is on supporting the Small and Medium Enterprises (SME). On the other hand, prototypes will be built to demonstrate the use of such frameworks. Cooperating support systems for virtual enterprises are designed with the goals of enabling the rapid creation and the use of a supporting infrastructure for virtual enterprises in specific industries, and of facilitating the establishment and the maintenance of efficient ways of cooperation among the partners of the business network and between partners and their customers.

\subsection{The Participants}

The VEGA* project is mainly financially supported by the Swiss Telecom PTT (Swisscom), and the CTI (The Swiss Federal Commission for Technology and Innovation) with academic and business partners (The University of Lausanne (Prof. A.-R. Probst, INFORGE-HEC), the University of Berne (Prof. J. Griese, IWI) the Swiss Federal Institute of Technology of Lausanne-EPFL (Prof. Cl. Petitpierre, LTI), as well as currently, the following enterprises: Swiss Telecom PTT (main sponsor principal), Linkvest S.A. (Renens) and Polydata-InformatikGruppe (Zurich)).

\section{CASE STUDIES}

The VEGA* project began with the gathering and analysis of business cases.

\subsection{Purpose}

We designed and made structured interviews (mainly face-to-face discussions) in order to build a set of practical case studies which were used to 
1. evaluate the potential of different industry sectors, i.e. the motivation and the capability of the enterprises within these sectors to adopt rapidly this new form of organization and of cooperation.

2. determine the main organizational and behavioural issues, as well as the first IS functional requirements.

The current business processes and Information management tools of the enterprises interviewed are evaluated in relation to the need of virtual organization. Organizational, behavioural and functional requirements are determined. We are trying also to discover generic patterns independent of an industry, as well as generic patterns within specific industries.

\subsection{Case studies analysis}

Currently 2 sets of case studies have been used:

a) Currently about 30 cases prepared especially for the VEGA* projects with enterprises belonging to different industries sectors in Switzerland. These cases were first exploited to determine the potential of different industry sectors in Switzerland.

b) About 30 cases in the IT sector mainly in Germany. These cases have been prepared by Pascal Sieber especially for the preparation of his doctoral thesis thesis (see e.g.: (Sieber, 1995), (Sieber, 1997) and (Sieber, Griese, 1997)) and kindly made available also for the VEGA* project. These cases have been first exploited to position specific enterprises in their evolution stages towards virtual organization.

Two analysis grids were used:

The first grid serves for the evaluation of the potential of industry sectors (see Figure 1). The potential for the implementation of an Internet based, cooperating support system was measured by the following four criteria:

- Adequacy of virtual structures: Concerning the formation of virtual structures, several requirements have to be met. Subcriteria to be examined are aspects of the value chain process as well as aspects of market structures.

- Motivation: For a detailed analysis of business processes as well as for the testing of a prototype, appropriate partners are required. Subcriteria relate to the competition induced need for action (implicit motivation) and the willingness to participate in a pilot (explicit motivation).

- Potential benefits of a software system: Evaluation of potential advantages by means of the extent of functionalities to be implemented.

- IT-support: Support of business processes, particularly the integration of Internet services in interorganizational business processes. 


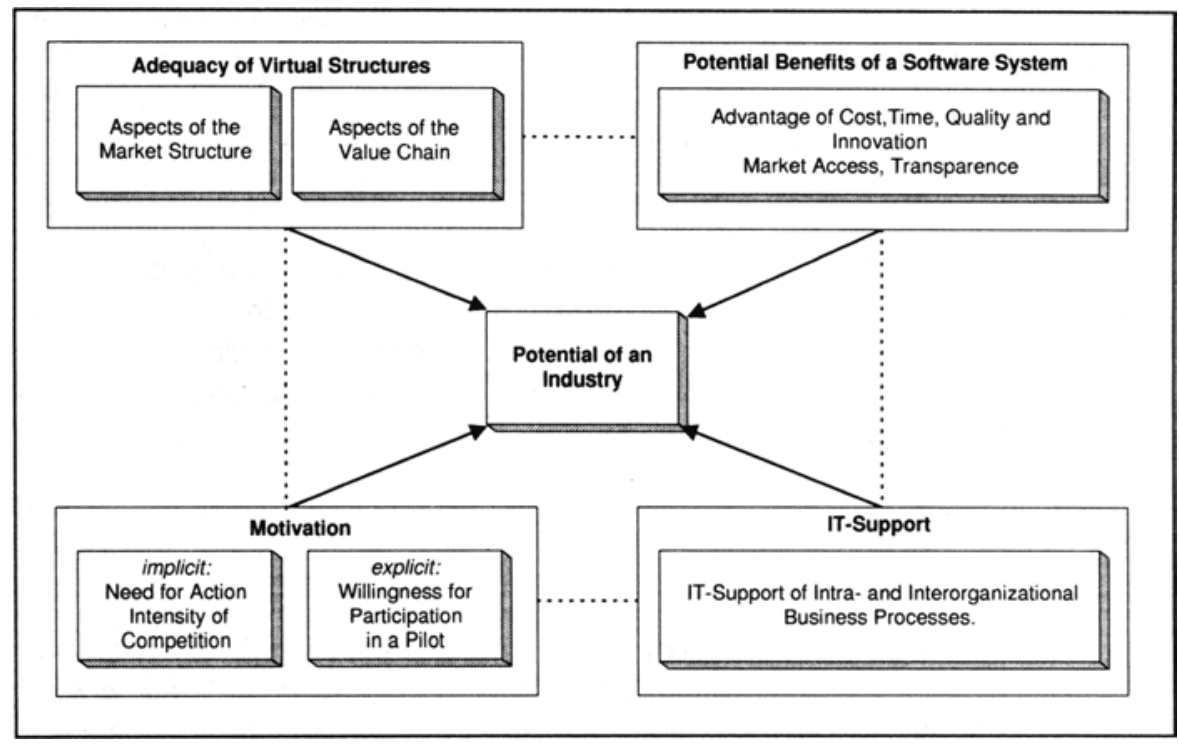

Figure 1 Criteria for industry sectors analysis.

As a result of a first analysis of 15 industries in Switzerland, the sectors of Information Technology (IT), Multimedia, Advertising and Microtechnology were chosen for a detailled evaluation. The final choice fell on the IT-Industry, namely on the businesses of IS-engineering and consulting services. The following statements will explain this decision.

- Adequacy of virtual structures: Concerning market structures, all four industries consist of a large number of small and medium enterprises. To offer global solutions, specialized enterprises are increasingly forced to cooperate for specific projects. Hence, there is a real need for the support of interorganizational business processes. The results of the study show that a main advantage of the IT-Industry is its ability to clearly define and execute modular tasks, the basis for a distributed value chain. Concerning the other three industries, face-to-face contacts are given more importance. For example, firms of the Microtechnology sector tend to form regional clusters to meet their communication needs.

The only disadvantage of the IT-Industry is the comparatively low cooperation culture. Because of lacking thrust, cooperation is often handled with scepticism, which usually leads to extensive contracting. The implementation of appropriate tools would make a contribution to overcome these barriers and therefore foster flexibility in terms of interorganizational cooperation.

- Motivation to participate in a pilot: The interviewed persons of the IT-sector were the most willing ones for collaboration. One important reason is that 
information and communication technologies are part of their daily business. Therefore, they have no fear facing new technologies. In comparison with other industries, the IT-sector has already a high penetration of the Internet technology. Moreover, some firms have already developed cooperation support systems on their own. Concerning the advertising industry, there are a lot of people who are mainly working in creative domains where technology rather plays a subordinated part. Advertising is a so-called "people-business", where social contacts are given a high importance. In addition, there is a real need for face-to-face contacts during the evaluation of provisional results (see adequacy of virtual structures). For this reasons, people of this industry may tend to be sceptical when facing new technologies as the Internet.

- IT-support: Considering the intraorganizational IT-support, there are no essential differences between the four evaluated industries. The difference lies at the level of interorganizational IT-support, namely the integration of Internet services in interorganizational business-to-business relations. Here, the ITIndustry takes again a distinct leading position.

- Potential benefits of a software system: The implementation of different functionalities might lead to essential advantages in cost, time and quality. Concerning all four Industries, there is a real potential for the support of project management processes and the use of a competence market. However, it seems that the IT-Industry would profit most by the use of a cooperate support system, because concerning the other three industries, the use of certain functionalities often fails due to too voluminous data to be transferred electronically. Today, transmission rates are usually too low for the transfer of e.g. CAD data. Hence, the transmission of data would be limited to simple documents - and therefore, the real potential of the Internet could not be fully exploited.

The second grid that was used (Venkatraman, 1995) serves for the determination of the stage of a specific enterprise in its evolution towards a virtual organization. This grid can also be used for strategy development.

According to (Venkatraman, 1995), virtualness can be divided into three dimensions (see Figure 2):

- "obtain and coordinate critical competences": competence leverage;

- "design of value-adding business processes and governance mechanisms": work configuration;

- "deliver differential, superior value": market experience; 


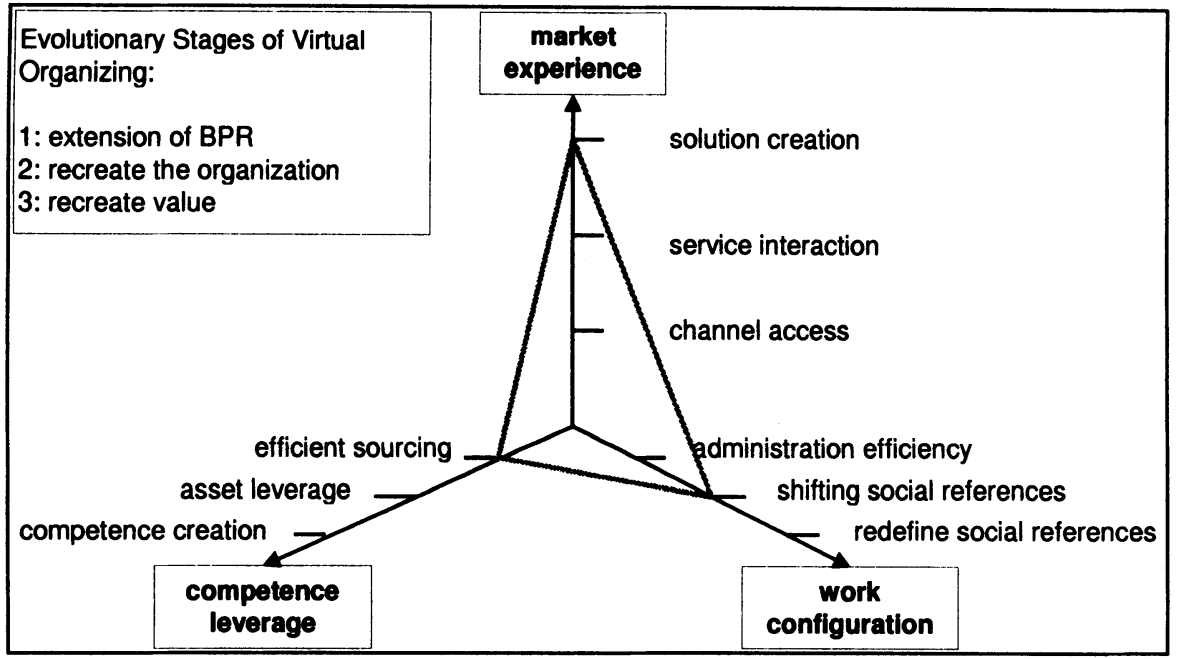

Figure 2 Dimensions and stages of virtual organizing (Venkatraman 1995).

These dimensions provide one of the methods used to analyse the business networks in our case studies.

To illustrate the influence of ICS on the virtualness of a company, three stages in the development of IT enabled business reconfiguration are proposed (see (Venkatraman 1995)):

1. Extension of BPR: the redesign of business processes is extended to external constituency mainly through the installation of EDI between different business partners to gain over all efficiency.

2. Recreate the organization: concentration on core competencies and building outsourcing partnerships to gain access to new markets as well as to share assets with external constituencies. This leads to more effective processes.

3. Recreate value: through the redesign of products and services exploiting modern ICS and combining external and internal modules of products, services and ICS, new value in the marketplace and market space (Rayport, Sviokla, 1995) is built.

The focus of a set of questions asked to the case study companies was on the actual temporary arrangements and on the virtualness of each company participating in virtual companies. Virtualness has to be seen as "the ability of the organization to consistently obtain and coordinate critical competences through its design of value-adding business processes and governance mechanisms involving external and internal constituency to deliver differential, superior value in the marketplace" (Venkatraman, Henderson, 1994). This formal definition gained a lot of empirical evidence through the case studies and therefore builds the basis of the first part of this work. 
This strategic and dynamic view shall be illustrated by some fragments of our case studies. The first coordinate to be discussed is work configuration:

A systems integrator in south Germany has been formalising all the processes of project management and designed a workflow management system (WMS) to possibly control most parts of the activities. The WMS is accessible through Web browsers what gives the employees a free choice of their working place (at home, in the office, at the customers' site). Project managers talk about an enhancement of capacities. They now can supervise more projects at the same time (administration efficiency). The idea of a software development company in Frankfurt is to give employees access to all relevant data in the company to enhance their capability. By doing so - through management information systems accessible by Web browsers - they soon recognised that many decisions do not have to be approved by directors, but can be made autonomously by project managers. The scope of this management layer has been enhanced (shifting social references). The final stage of virtualness in the work configuration dimension can be illustrated by a software development company in Munich: every year, some of the about 20 employees start their own company. By doing so they do not change the range of their activities. Rather they become partners of their former employer. As a result, this company remains relatively small, However a business network has grown over the last ten years, that delivers management information tools in the whole Europe and sometimes even overseas (redefine social references).

In the dimension of competence leverage the stage one - efficient sourcing - can not be illustrated by our case studies because many of the service oriented IT companies do not rely on suppliers in the classical sense. What asset leverage can mean is illustrated by a software company in Leipzig which five years ago recognised that it can not survive with its narrow business scope. To broaden the scope of their products, heavy investments would have been needed, and the company had no possibility to finance them. In this situation the company was looking for partners that provide complementary modules to its own software. By 1994 a business network was built that sells, maintains and supports an integrated standard software for medium sized companies. Every component can be installed independently and the whole product costs about $1 / 5$ of comparable products sold by competitors. One of the problems that arise in such open business networks is the maintenance of knowledge. The above mentioned software company in Munich demonstrates one possibility to achieve this goal. It built strong relationships to several Universities and private research institutions. Together with these constituencies it conducts - as an industry partner - several research projects at a time. The results of the projects are combined with existing products or - which is more often the case - are taken as basis for the development of new products. Over the last twelve years the company has been building a large knowledge base that contains all the descriptions and the estimated potential of outcomes to become useful by maintaining the companies' products (competence creation). 
Finally some illustrations about leveraging market experience: often SME have access only to local markets. Larger companies more and more gain access to these local markets and start to compete - often through substitutes - with the SME. Some 15 companies trading with hard- and software built an alliance supported by a virtual corporate network on the basis of combined Internet/Intranet applications. Every company is specialised in the support of a bundle of products. Through the network of companies each small company with its specialised competencies gains access to several regions throughout Austria, Germany and Switzerland (channel access). By combining hardware, software and services delivered by different companies a network of companies in Switzerland manages to enhance the business scope above the level one single company could possibly reach. Through a joint Web site that is maintained decentrally the customer is provided a broad range of interactive components (service interaction). The most obvious stage in the market experience dimension for IT companies is solution creation. As most of the software products need to be applied to the special environment at the customers site nearly every company we met integrates the customers in the creation of value. The roles of customers and suppliers most often seem to vanish. The only feature of the entities remaining is that in the end the customer pays the supplier a certain amount of money for his help building or maintaining a system (solution creation).

In investigating several SME that are using ICS to support and build business networks we recognised that - contrary to big companies - the path of development of virtualness is not through BPR and outsourcing to gain efficiency but rather through differentiation. The primary need for ICS in SME is not so much the need for automation through formalization and support of well-structured information exchange. SME need sophisticated communication systems to exchange unstructured information and only in further stage of their development of virtualness they will integrate these systems, and then will need systems for automated data exchange and representation of knowledge. Further, we found that the SME cope with a much more dynamic environment changing partnerships more often than large companies do, and participating in projects with companies they never met before. The ICS support therefore has to be built on an open platform. Compatibility, scalability and interoperability are very important features. As a third outcome of our study we saw that SME have not adopted very complex ICS so far. They are, in general, not heavy users of ICS and do not invest in strategic information systems. The tool set to be implemented therefore has to be oriented at "standard" software (such as Microsoft Office or Lotus Notes, for example) with an easy to use front end and great transparency. But such software alone is not sufficient. 


\section{THE CHALLENGE OF ADAPTING THE BUSINESS PROCESSES' VALUE CHAIN}

For virtual enterprises as for conventional organizations the value chain of the enterprise is described by a set of business processes related to the Customer Activity Cycle (Probst, Wenger, 1997b). This begins with awareness creation and ends with support services. The objective is to integrate the customer into the system in order to achieve "Total Customer Care"

The main business processes which were identified as requiring important transformation of the conventional enterprise business processes as well as the availability of new types of IS support are:

- The virtual enterprise organization set up and development process (with the qualification process for belonging to the Virtual Enterprise network).

- The competence management process.

- The VE management by projects process.

- The customer relationship management process (total customer care, including the marketing and sales processes);

- The VE coaching process.

\section{PERSPECTIVES}

To better asset the requirements as well as to be able to translate immediately concepts into practical tools, prototyping is used continuously in the VEGA* project. The insights gained in analysing practical cases are exploited in concurrently expanding a prototype of the VEGA* system. This prototype is in turn used to get more practical feedback on concrete users requirements.

The VEGA* system is designed to be open, distributed, scalable, evolutive, to facilitate the integration of existing systems and the interconnection of heterogeneous partners' systems.

Thus, a multi-agents architecture (Fischer et al., 1996) providing knowledgebased services facilities has been designed (see for example: (Probst, Wenger, 1996a), (Probst, Wenger, 1996b), (Wenger, Probst, 1997a)). Such an architecture

- is built upon the infrastructure consisting of Internet / Intranets and the Web (in order to take advantage of the increasing number of available products offered within this environment, and of the emerging standards).

- can use the administrative facilities offered by operational applications, including EDI.

The practical cases analysed until now have shown that successful virtual enterprises alliances are built within a network of potential partners (qualification procedure screens the enterprises which can belong to this business network). The 
pool of enterprises of a business network constitute a pool of resources, competencies, knowledge, skills and experience, from which virtual enterprises will be built for specific projects, in order to be able to take together advantage of business opportunities.

We have thus divided the knowledge-based services provided by agents into three categories:

1. services for the partners community (the pool of enterprises belonging to the business network), such as competencies bases, cases bases,

2. services for setting up and supporting virtual enterprises built for specific projects, total quality management procedures,

3. services for supporting and leveraging specific competencies of the partners, to be used during a project, or afterwards for customer care.

These services are related to the requirements which have already been derived from the cases evaluated up to now.

Another important aspects which will be studied is the impact of the development of communities on virtual enterprises' organizations. As mentioned by (Hagel, Armstrong, 1997) the rise of virtual communities in on-line networks has set in motion an unprecendented shift in power from vendors to customers. The design of efficient electronic relationships within customers communities and between them and the virtual enterprises will certainly induce more transformations in the business processes, especially in a business-to-business context. These aspects will also be examined in the VEGA* project.

\section{REFERENCES}

Arnold, O.; Faisst, W.; Härtling, M.; Sieber, P. (1995) Virtuelle Unternehmen als Unternehmenstyp der Zukunft?, in: Handbuch der modernen Datenverarbeitung 32 (1995) 185, S. 8- 23.

Bentley, R.; Horstmann, T.; Sikkel, K.; Trevor, J. (1995) Supporting Collaborative Information Sharing with the World Wide Web - The BSCW Shared Workspace System, in: Proceedings of the 4th International WWW Conference, Boston 1995.

Birchall, D.; Lyons, L.: Creating Tomorrow's Organization: Unlocking the Benefits of Future Work, London 1996.

Chesbourgh, H.W.; Teece D.J.: When is Virtual Virtuous? Organizing for Innovation, in: Harvard Business Review 74 (1996) 1, p. 65-73.

Collins, J.C.; Porras, J.I. (1995) Built to Last: Successful Habits of Visionary Companies, London 1995. 
Davidow, W.H.; Malone, M.S. (1992) The Virtual Corporation: Structuring and Revitalizing the Corporation for the 21st Century, New York 1992.

Erkes, J.W.; Kenny, K. B.; Lewis J. W.; Sarachan, B. D.; Sobolewski M. W.; Sum, Jr. (1996) Implementing Shared Manufacturing Services on the World Wide Web, in: Communications of the ACM 39 (1996) 2, p. 39-45.

Fischer, K.; Müller J. P.; Heimig, I.; Scheer, A.-W. (1996) Intelligent Agents in Virtual Enterprises, in: Proceedings of PAAM96 - The First International Conference on "The Practical Applications of Intelligent Agents and Multi-Agent Technology", London 1996, p.205-223.

Frankwick, G.; Elston, K.; Laubach, L. (1995) Motivators and Barriers to Participation in a Virtual Enterprise, Oklahoma State University 1995, http://catt.bus.okstate.edu/catt/phase-1/motivate.html.

Goldman, S.L.; Nagel, R.N.; Preiss K. (1995) Agile Competitors and Virtual Organizations, New York 1995.

Goldschmidt, A. (1996) Report on NIIIP, in: Communications of the ACM 39 (1996) 3, p. 100-103.

Grenier, R.; Metes, G. (1995) Going Virtual: Moving your Organization into the 21st Century, New Jersey 1995.

Griese, J. (1997) Virtuelle Unternehmen - State of the Art, Teilnehmerunterlagen zum Workshop "Virtualität als Wettbewerbsvorteil", Institut für Wirtschaftsinformatik der Universität Bern, Bern 1997.

Hagel, J.; Armstrong, A.G. (1997) Net Gain: Expanding Markets through Virtual Communities, Boston 1997.

Handy, C. (1995) Trust and the Virtual Organization - How do you manage people whom you don't see?, in: Harvard Business Review 73 (1995) 3, p. 40-50.

Hardwick M.; Spooner D.L.; Rando, T.; Morris, K. (1996) Sharing Manufacturing Information in Virtual Enterprises, in: Communications of the ACM 39 (1996) 2, p. 46-54.

Heskett, J. L.; Sasser Jr, W.E.; Schlesinger, L. A. (1997) The Service Profit Chain, New York 1997.

Hinterhuber, H.H.; Levin, B. M. (1993) Strategic Networks - The Organisation of the Future, in: Long Range Planning 27 (1993) 3, p. 43-55.

Maier, G., Traxler, H. (1995) The Emergence of the Virtual Enterprise: How Austrian companies use the Internet, in: Proceedings of the 35 th European Congress of the Regional Science Association, Odense 1995. 
Maillat, D.; Crevoisier, O.; Lecoq, B. (1990) Réseaux d'Innovation et Dynamique Territoriale: L'Arc Jurassien, Dossiers Université de Neuchâtel, IRER, Neuchâtel 1990.

Martin, J. (1996) Cybercorp: The New Business Revolution, New York 1996.

Mertens, P.; Faisst, W. (1995) Virtuelle Unternehmen - eine Organisationsstruktur für die Zukunft?, in: Technologie \& Management 44 (1995) 2, p. 61-68.

Moore, J.F. (1996) The Death of Competition: Leadership and Strategy in the Age of Business Ecosystems, Cambridge-Massachusetts 1996.

NIIIIP Consortium (1996) NIIIP Reference Architecture (Revision 6), Report No. NTR95-01, http://www.niiip.org/public-forum/index-public-documents.html.

Probst, A. R.; Bitschnau, J.-F.; Petitpierre, C. (1996) Environnement de communication et de collaboration pour un nouveau type d'organisation d'entreprise: l'entreprise virtuelle, Rapport projet UNIL-EPFL, Lausanne 1996.

Probst, A. R.; Wenger, D. (1996a) Reconciling Business Process Reengineering and Information System Design, in: Proceedings of the COST4 Worshop on "Assessing Business Process Redesign and its IT Implications", EPFL, Lausanne 1996.

Probst, A. R.; Wenger, D. (1996b) Improving Enterprise Leadership Capabilities: An Agent Based Business Service Modeling Approach, in: Proceedings of the NBPR'96 Conference, Washington 1996.

Rayport J. F., Sviokla J. J (1995) Exploiting the Virtual Value Chain, in: Harvard Business Review 73 (1995) 6.

Sieber, P. (1995) Die Dr. Materna GmbH auf dem Weg zum Virtuellen Unternehmen?, Arbeitsbericht Nr. 74, Institut für Wirtschaftsinformatik der Universität Bern, Bern 1995.

Sieber, P. (1997) Präsentation von Fallstudien Virtueller Unternehmen, Teilnehmerunterlagen zum Workshop "Virtualität als Wettbewerbsvorteil", Institut für Wirtschaftsinformatik der Universität Bern, Bern 1997.

Sieber, P.; Griese, J. (1997): Virtual Organizing as a Strategy for the "Big Six" to Stay Competitive in a Global Market, in: Proceedings of the 30th Hawaii International Conference on System Sciences, Hawaii 1997.

Upton, D.M.; McAfee, A. (1996) The Real Virtual Factory, in: Harvard Business Review 74 (1996) 4, p. 123-133.

Venkatraman, N.; Henderson, C. (1994) "Avoiding the Hollow": Virtual Organizing and the Role of Information Technology, http://web.bu.edu/SMGSRC/projects/virtual.html. 
Venkatraman, N. (1995) The IS Function in the Virtual Organization: Who's Wagging Whom?, in: Panel 10 of the Sixteenth International Conference on Information Systems, Amsterdam 1995, p. 378.

Wenger, D.; Probst, A.R. (1997a) Synthesizing Business and Information Systems: Towards a common Business-IS Model based on Agents, in: Proceedings of the WI'97 Business Informatics 1997 Conference, Berlin 1997.

Wenger, D.; Probst, A.R. (1997b) Commerce électronique et systèmes de gestion des relations avec les clients: "Total Customer Care", in: Proceedings of the Conférence 1997 MBA HEC Lausanne, Lausanne 1997, p. 115-130.

\section{BIOGRAPHY}

Probst, André R.: MS (diplôme d'ingénieur-physicien) in 1962 and $\mathrm{PhD}$ in Applied Mathematics (Dr. ès sciences techniques) in 1966, both from the Swiss Federal institute of Technology of Lausanne (EPFL). Associate Professor (Information Systems) at the Business Faculty (HEC) of the University of Lausanne (part time). Manager of the KMU (Knowledge Management Unit) of the institute INFORGE of the University of Lausanne. Consulting activities with international companies. Teaching and Research activities: Information Systems, Decision Support and Management Support Systems, Knowledge-based, "intelligent", and cooperating systems, Virtual Enterprises Support Systems.

Bitschnau, Jean-François: Licence HEC (1993) and Master in Business Information Systems, University of Lausanne (1994). Assistant at the KMU (Knowledge Management Unit) of the institute INFORGE of the University of Lausanne. Research activities (preparation of a doctoral thesis): Information systems for virtual enterprises.

Griese, Joachim: MS in mechanical engineering 1966 and business administration 1968, $\mathrm{PhD}$ in business administration 1970. Tenured Professor at the Business Faculty of the University of Dortmund (Germany) 1974-1983, since 1983 Director of the Institute for Information Systems at the University of Berne (Switzerland). Current research activities: organizational aspects of information systems.

Suter, Benno: Diploma in business administration at the University of Berne 1996. Assistant at the Institute of Information Systems at the University of Berne since October 1996. Research activities: Internet support for Virtual Organizations. 